Mini Review

\title{
Nebivolol: a different beta-blocker for hypertension
}

\begin{abstract}
Beta blockers are one of the classes of antihypertensive drugs, but there are controversies of their use as an initial therapy in treatment of arterial hypertension based on different guidelines for treatment of arterial hypertension. Nebivolol is a third generation, highly selective $\beta$-adrenoceptor antagonist with antihypertensive efficacy similar to other beta blockers but with unique function of increasing the release of nitric oxide (NO) via activation of $\beta 3$-adrenergic receptors which improves endothelial function, produces vasodilatation, improves arterial compliance and reduces peripheral vascular resistance. Nebivolol highly selective lipophilic B1-adrenergic receptor antagonist and B3 agonist has different pharmacokinetics and pharmacodynamics profile from other beta blockers with more favourable metabolic and hemodynamic profile, like side effect profile, beta receptors blockade affinity, vasodilating properties, and improvement of endothelial function. Nebivolol has been show to be effective beta blocker for treatment of mild to moderate arterial hypertension as monotherapy or in combination therapy.
\end{abstract}

Keywords: beta blockers, nebivolol, endothelial function, nitric oxide

Volume 5 Issue 4 - 2016

Otljanska M, Kostova N, Boshev M, Otljanski A

University Clinic of Cardiology, Medical Faculty, University "Sts. Cyril and Methodius", Macedonia

Correspondence: Otljanska Magdalena, University Clinic of Cardiology, Medical Faculty, University Campus "Mother Theresa"-Skopje, Republic of Macedonia, Tel 38972 23I 006, Email magdalenaotljanska@gmail.com

Received: March 20, 2016| Published: April 19, 2016

\section{Introduction}

Beta blockers have been used widely since 1970 in treatment of arterial hypertension and in last few years there are controversies of use of beta blockers as an initial therapy in treatment of arterial hypertension. Beta blockers for many years have been established as first line therapy in management of hypertension, but the last guidelines from JNC 8 and NICE guidelines from 2011 put them in the second line of treatment of arterial hypertension. When we look at the European guidelines for treatment of hypertension from 2013, we have to choose from the five major antihypertensive drugs classes as an initial therapy in which beta blockers are one of them: diuretics, ACE inhibitors, calcium antagonists, angiotensin receptor blockers, and B-blockers. They do not differ significantly for their overall ability BP reduction in hypertension but they do differ in their ability to protect against overall cardiovascular risk of causespecific cardiovascular events, such as stroke and myocardial infarction (Table $1){ }^{1}$

Table I Clinical conditions in hypertensive patient when beta blockers are indicated

\begin{tabular}{ll}
\hline Previous stroke & Any BP lowering agent \\
\hline $\begin{array}{l}\text { Previous MI } \\
\text { Angina pectoris }\end{array}$ & BB, ACE-I, ARB \\
Heart failure & $\begin{array}{l}\text { DB, CA } \\
\text { Diuretics, BB, ACE-I, ARB, } \\
\text { atialdosterone agents }\end{array}$ \\
$\begin{array}{l}\text { Atrial fibrillation, } \\
\text { permanent }\end{array}$ & BB, non-dihydropiridine CA \\
\hline
\end{tabular}

Source: ESH/ESC Guidelines for the management of arterial hypertension 2013.

The goals of antihypertensive treatment in hypertensive patients is the maximum reduction in long-term total risk of cardiovascular disease, requiring a reduction in raised blood pressure and treatment of all associated reversible risk factors. ${ }^{1}$ Beta blockers are heterogenic group of antihypertensive drugs who have many differences in pharmacokinetic and pharmacodynamic profile like side effect profile, maintenance of exercise tolerance, improvement of endothelial function, sympathomimetic activity, beta receptor blockade affinity, vasodilating properties etc.(Figure 1). ${ }^{2}$

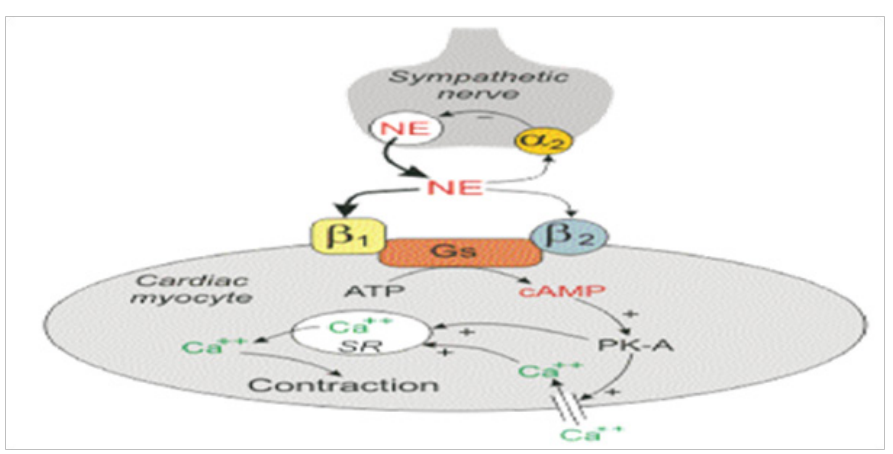

Figure I Mechanism of action of beta blockers.

Essential hypertension is a condition associated with endothelial dysfunction which is caused by production of oxygen free radicals that destroy nitric oxide and impair its beneficial and protective effects on vessel wall (Figure 2). . $^{3,4}$

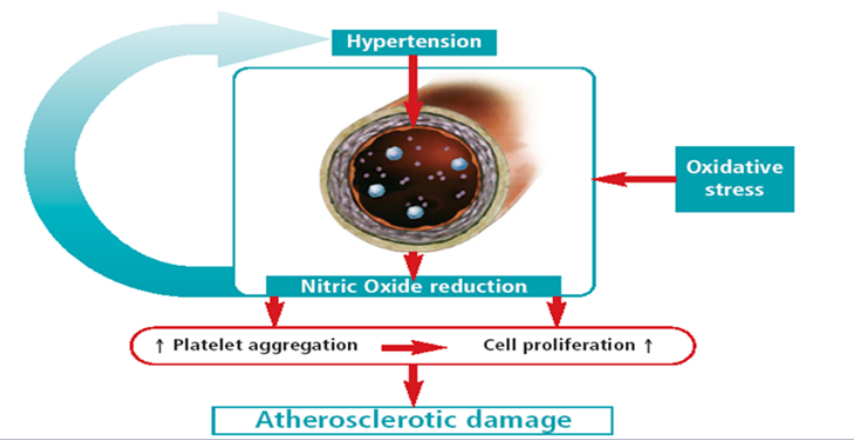

Figure 2 Endothelial dysfunction in hypertension. Nebivolol was first introduced in UK in 1999 for treatment of essential hypertension.

Nebivolol is a third generation beta blocker, highly selective $\beta$ adrenoceptor antagonist indicated for treatment of essential hypertension and heart failure (in Europe). The third-generation betablockers are distinguished from the earlier classes of beta-blockers by their vasodilating activity. Nebivolol in essential hypertension is indicated in mild or moderate hypertension alone or in combination 
therapy. Nebivolol is beta 1 antagonist and beta 3 agonist. This beta blocker have a unique function to increase the release of nitric oxide (NO) via activation of $\beta 3$-adrenergic receptors, improving endothelial function, producing vasodilation, improving arterial compliance and reducing peripheral vascular resistance. Due to its unique mechanism of action, nebivolol offers some central hemodynamic effects. ${ }^{5,6}$

Nebivolol is administered as a racemic mixture of equal proportions of "d" and "l" isomers. Nebivolol has 4 asymmetric centres, d-isomer refers to $(\mathrm{S}, \mathrm{R}, \mathrm{R}, \mathrm{R})$-nebivolol and 1-isomer to $(\mathrm{R}, \mathrm{S}, \mathrm{S}, \mathrm{S})$-nebivolol. Antihypertensive effects of nebivolol appear to be greater with both isomers than with the d-isomer alone. Nebivolol exhibits greater degree of beta 1/beta 2-receptor selectivity compared with other commonly used beta-blockers.

The selectivity of Nebivolol on the beta 1-adrenergic receptor is 321-fold higher than for beta 2-adrenergic receptor. Conventional beta blockers are associated with unfavorable effects on metabolic parameters. Nebivolol has favorable metabolic profile, with no deleterious effect on insulin sensitivity which may result from its agonistic activity on the beta 3 adrenoreceptor. This beta blocker exhibits anti-proliferative and antioxidant properties. ${ }^{7}$

The efficacy and tolerability of nebivolol have been evaluated in comparison with placebo and other beta-blockers (atenolol, bisoprolol - Nebis Study, metoprolol) and other antihypertensive drugs. Nebivolol has good pressure-lowering effect in hypertensive patients (2838 pts) with type 2 diabetes mellitus-Yestono Study. Because many antihypertensive drugs especially beta blockers affect erectile function, Nebivolol may be appropriate alternative in patients with erectile dysfunction. ${ }^{3,8}$

Some study analyze the influence of Nebivolol on postmenopausal women, due to the possibility that some symptoms like hot flashes may be associated with decreased NO production and release.

\section{Conclusion}

Nebivolol is a third generation beta blocker indicated for treatment of mild to moderate hypertension with a unique function to increase the release of nitric oxide (NO) via activation of $\beta 3$ adrenergic receptors. This unique mechanism of action may be reflected in nebivolol's advantageous hemodynamic and tolerability profile, compared with other beta-blockers. Nebivolol has also demonstrated antihypertensive efficacy similar to that of other beta-blockers and other antihypertensive classes.

\section{Acknowledgments}

None.

\section{Conflicts of interest}

Authors declare that there is no conflict of interest.

\section{References}

1. Mancia G, Fagard R, Narkiewicz K, et al. 2013 ESH/ESC Guidelines for the management of arterial hypertension: the Task Force for the management of arterial hypertension of the European Society of Hypertension (ESH) and of the European Society of Cardiology (ESC). J Hypertens. 2013;31(7):1281-1357.

2. Weiss R. Nebivolol: A Novel beta-blocker with Nitric Oxide-induced vasodilation. Vasc Health Risk Manag. 2006;2(3):303-308.

3. Bowman AJ, Chen CP, Ford GA. Nitric oxide mediated venodilator effects of nebivolol. Br J Clin Pharmacol. 1994;38(3):199-204.

4. Tzemos N, Lim PO, MacDonald TM. Nebivolol reverses endothelial dysfunction in esential hypertension: a randomized, doubleblind, crossover study. Circulation. 2001;104(5):511-551.

5. McEniery CM, Schmitt M, Qasem A, et al. Nebivolol increases arterial distensibility. Hypertension. 2004;44:305-310.

6. Maffei A, Lembo G. Nitric oxide mechanism of Nebivolol. Ther Adv Cardiovasc Dis. 2009;3(4):317-327.

7. Munzel T, Gori T. Nebivolol: The Somewhat-different B-adrenergic beta blocker. J Am Coll Cardiol. 2009;54(16):1491-1499.

8. Sahana GN, Sarala N, Kumar TN. Nebivolol - pharmacological aspects. Int J Biol Med Res. 2011;2(2):577-580. 